\title{
Credibility of Digital Political News in Spain: Comparison between Traditional Media and Social Media
}

\author{
Reinald Besalú *(D) and Carles Pont-Sorribes (D) \\ Department of Communication, Barcelona School of Management, Pompeu Fabra University, \\ 08002 Barcelona, Spain; carles.pont@upf.edu \\ * Correspondence: reinald.besalu@upf.edu; Tel.: +34-9-3542-2447
}

Citation: Besalú, Reinald, and Carles Pont-Sorribes. 2021. Credibility of Digital Political News in Spain: Comparison between Traditional Media and Social Media. Social Sciences 10: 170. https://doi.org/ 10.3390/socsci10050170

Academic Editor:

Andreu Casero-Ripollés

Received: 19 April 2021

Accepted: 2 May 2021

Published: 13 May 2021

Publisher's Note: MDPI stays neutral with regard to jurisdictional claims in published maps and institutional affiliations.

Copyright: (c) 2021 by the authors. Licensee MDPI, Basel, Switzerland. This article is an open access article distributed under the terms and conditions of the Creative Commons Attribution (CC BY) license (https:// creativecommons.org/licenses/by/ $4.0 /)$.

\begin{abstract}
In the context of the dissemination of fake news and the traditional media outlets' loss of centrality, the credibility of digital news emerges as a key factor for today's democracies. The main goal of this paper was to identify the levels of credibility that Spanish citizens assign to political news in the online environment. A national survey $(n=1669)$ was designed to assess how the news format affected credibility and likelihood of sharing. Four different news formats were assessed, two of them linked to traditional media (digital newspapers and digital television) and two to social media (Facebook and WhatsApp). Four experimental groups assigned a credibility score and a likelihood of sharing score to four different political news items presented in the aforementioned digital formats. The comparison between the mean credibility scores assigned to the same news item presented in different formats showed significant differences among groups, as did the likelihood of sharing the news. News items shown in a traditional media format, especially digital television, were assigned more credibility than news presented in a social media format, and participants were also more likely to share the former, revealing a more cautious attitude towards social media as a source of news.
\end{abstract}

Keywords: credibility; likelihood of sharing; political digital news; Facebook; WhatsApp; digital television; digital press; Spain

\section{Introduction}

The notion of fake news has become widespread in recent years, especially since the 2016 US presidential elections. ${ }^{1}$ However, the concepts and the implications of inaccurate, flawed, unverified or fake news have been studied since the early 20th century (Giglietto et al. 2019).

The classical literature on news creation indicates that a source's prominence influences the credibility assigned to the news, even by journalists (Tuchman 1978), leading to a privilege for institutionalised sources. However, today we are witnessing a loss of trust in the press as a democratic institution (Bennett and Livingston 2018), just as the new digital media are enabling political and institutional actors to leap over the flow of communication, which may include fake news. While at the same time, the more partisan media are contributing to making viral this flawed news, as proven by different studies on fake news (Vargo et al. 2018). Therefore, the obstacle to combatting disinformation or fake news is not only its creation but also its instantaneous propagation by means of multiple news channels, especially the social media.

Given all of this, it is clear that the credibility of the news that circulates in an online environment is an important factor when studying the phenomenon of disinformation, fake news, and the loss of trust in the traditional media, in that it can explain its scope or influence. In this sense, Go et al. (2016) offer an interesting reflection on the relationship between credibility and trust. According to these authors, the research tradition in media psychology has often focused on the concept of credibility as an individual perception, while the research tradition in media sociology has preferred to use the broader term "trust", which is associated with social capital. Nonetheless, as these authors and others 
like Tsfati (2010) point out, credibility should be understood as a core component of trust in the media, that is, as an individual indicator which, along with others, enables the level of trust in the media on a societal level to be evaluated.

However, credibility is not objective but instead a personal perception about the quality of news. Therefore, it is important to study audiences to evaluate their perceptions of the credibility of news items. In this study, we examined how the Spanish population over the age of 18 perceives this news in order to ascertain the degree of credibility they assign to the different media and platforms in the online environment: newspapers, television, Facebook, and WhatsApp.

The Spanish case is relevant because authors such as Bernal-Triviño and ClaresGavilán (2019) have already proved that the credibility of political information is an important issue for Spaniards in a context of concern for the possible effects of the socalled fake news in shaping public opinion. This fact, together with the consolidation of the so-called hypermedia space, points to the idea that new media, platforms and devices have a significant impact in news credibility. This is the conclusion of the study of Varona-Aramburu et al. (2017), in which they state that, in Spain, mobile devices have become the first gateway to the internet, thus transforming the way the public obtains information and interacts with news content. Moreover, Spain is one of the European countries with the less credible press, according to different studies. For example, the Reuters Institute Digital News Report 2015: Tracking the future of news ${ }^{2}$, studied the level of trust in the news by citizens of 12 European countries, and Spain was the second-to-last country, with only $32 \%$ of citizens trusting the news, far from the levels in Finland (68\%). Finally, a Pew Research Center ${ }^{3}$ study comparing Denmark, Germany, The Netherlands, Sweden, United Kingdom, Italy, Spain, and France highlights the fact that the Southern European countries have lesser trust in their media. In Spain, specifically, only $31 \%$ of citizens show trust in the news they receive, far from the first country in the ranking (The Netherlands, with $67 \%$ of its citizens trusting the news from their local media).

\section{Literature Review}

\subsection{News Credibilty}

The research into news credibility is extensive and prolific from both the academic and industrial vantage point, and it has a longstanding tradition. The majority of authors concur in stating that news credibility can be addressed on three levels: source credibility (that is, the credibility of specific titles), medium or media credibility (that is, the credibility of television or newspapers or radio in general, for example), and content or message credibility (that is, the credibility of a specific news story) (Kiousis 2001; Bucy 2003; Chung et al. 2012; Blach-Ørsten and Burkal 2014). Even though all three essentially seek to study how certain news components are associated with certain levels of credibility, it is clear that different elements are emphasised. Thus, in source credibility, the qualities of the communicator are an essential factor. In contrast, in medium credibility, the specific and socially recognised ways that the news is presented in every medium are ultimately the determining factors. Finally, when evaluating content credibility, the use of language, the way a specific news item is organised and presented and its sources, attribution processes (Hong 2021), as well as the event reported itself, all bear an influence.

So, what are the components of credibility? As Sundar (1999) and Blach-Ørsten and Burkal (2014) suggest, credibility has often been evaluated based on synonyms that end up being somewhat ambiguous, abstract. and generic, just like the notion of credibility itself (for example, based on the concept of believability). However, there does seem to be a somewhat solid agreement among the scholarly community in considering that trustworthiness and expertise are the two main sub-dimensions of credibility, especially source credibility (Bucy 2003; Chung et al. 2012; Choi and Kim 2017). Others advocate for a broader definition of credibility that also includes the community affiliation dimension, or, more recently, dimensions inherent to the online environment such as hypertextuality and interactivity (Chung et al. 2012). In any event, researchers tend to construct credibility 
indexes by presenting a series of informational qualities associated with each of these dimensions (such as objectivity, impartiality, accuracy, precision, or veracity) and asking informants to evaluate their presence in the news item using a Likert scale (this is the option chosen by Miller and Kurpius 2010; Bucy et al. 2014; and Choi and Kim 2017, among others). Yet as mentioned above, these qualities are often as ambiguous as the concept of credibility itself.

\subsection{The Factors That Explain the Credibility Assigned to News}

Different studies have examined the factors that influence the perception of credibility beyond the source, the medium, and the content of the news story. For example, it has been pointed out that the use and consumption of news practices in general (Roses and Gómez-Calderón 2015) and the Internet specifically-especially checking digital newspapers (Go et al. 2016) —affect the credibility levels assigned to news. Other studies underscore the importance of relying on certain news sources in perceptions of credibility (Johnson and Kaye 1998, 2014) or point to news coverage as a key factor for credibility (Rodríguez-Fernández et al. 2020). And yet others cite the tendency to discuss news in interpersonal communication as an important factor when assigning low credibility to television news (Kiousis 2001), or when assigning more or less credibility to liberal and conservative media outlets, depending on the kind of interpersonal discussion at stake (supportive or opposing) (Hmielowski et al. 2020). However, the possibility of evaluating the credibility assigned to news based on the actions that users take with it in the online environment (sharing and discussing it via the social media), which would transfer the tendency to discuss the news that Kiousis (2001) mentions to the virtual sphere, has barely been explored (although the study of Pjesivac et al. (2018), focused on how online comments in the news affect the assessment of its credibility, is one interesting contribution in this sense). Likewise, the fact that individuals' interest in the topics discussed in the news may be related to the credibility they assign to it has scarcely been evaluated. We thus pose the following hypotheses:

Hypothesis 1.1. The credibility assigned to news in the online environment is associated with a desire to share it via the social media.

Hypothesis 1.2. The credibility assigned to news in the online environment is associated with the interest in the topics covered by the news.

On the other hand, age has been noted as a factor that conditions the perception of credibility. Nonetheless, there are no conclusive results on the direction of this relationship. Fogg et al. (2001) and Choi and Kim (2017) state that young people are more critical and therefore less likely to assign credibility to the news, while in a study on the perception of credibility of the media in Spain, Roses and Gómez-Calderón (2015) explain that older informants, as well as those with higher educational levels, assign lower levels of credibility to news stories (as already found by Bucy 2003). In the case of the social media as news sources, Johnson and Kaye (2014) also found that young people assign them higher credibility. In any event, bearing in mind that this study focuses on Spaniards' perceptions, we posited the following hypotheses:

Hypothesis 2. The level of credibility assigned to the news in an online environment is negatively affected by age.

\subsection{Format or Genre Credibility}

Even though media credibility is conceptually different from source credibility, when researching them it becomes clear that they are rather difficult to separate, since there are aspects that permeate both (Kiousis 2001). Therefore, the indicators to evaluate media credibility often differ little from those used to study source credibility. For example, Flanagin and Metzger (2000) constructed a composite index on the perception of the believ- 
ability, accuracy, trustworthiness, bias, and completeness of the news found in newspapers, radio, television, and the Internet. Kiousis (2001), in turn, compared the perceptions of the credibility of news items in newspapers, television, and online by asking the respondents about their degree of factuality, motivation for money, privacy, community concern, and trust. While the results in the latter study show that the medium assigned the highest credibility is newspapers, followed by online news and television, Flanagin and Metzger (2000) conclude that newspapers are the only medium with more credibility than the other media, whose levels of credibility show no statistically significant differences.

In any event, these two studies were conducted at a time when the presence of online news had just begun, and when many of the formats and mechanisms by which the news reaches users today were still being defined. The first factor worth bearing in mind in this sense is that it is not very practical to consider the Internet as a means of communication that can be evaluated as a whole in terms of its credibility. Currently, the Internet includes all the news formats of the traditional media along with new ones. Thus, the digital news environment reaches users by many avenues and in different formats: social media, digital newspapers (native and not), IP television, chats, aggregators, etc. In the conclusions of his study, Kiousis (2001) himself warned that one of the factors that must be addressed is how we define "online news", a concept which is ambiguous for both researchers and subjects. Therefore, it is essential to evaluate how different types of online news may be related to different levels of credibility. In this sense, for example, Go et al. (2016) analyse the perception of the credibility of online news according to whether it is provided by portals, digital newspaper websites, or the social media, and Chung et al. (2012) distinguish between three online news sources: mainstream, independent, and aggregators.

Flanagin and Metzger (2007) propose the concept of "genre" to refer to the different environments in which news can be "embedded" on the Internet (they distinguish between news media websites, special interest sites, e-commerce sites, and personal sites), and they prove that genre affects the perception of credibility (although they admit that it can be masked by the characteristics or attributes of the sites evaluated). Seven years later, Johnson and Kaye (2014) took the concept of "genre" and applied it to the political news that appears in the social media, political websites, candidates' websites, political blogs, candidates' blogs, YouTube, television news broadcast online, cable television news shown online, and digital newspapers. The authors also state that: "the Internet is comprised of several components, such as SNS [social network sites] and blogs. Because each component is different from one another in terms of interactivity, synchronicity, how information is retrieved, how it is used, and users' expectations, the credibility of each is judged by different criteria" (Johnson and Kaye 2014, p. 959).

Therefore, it could be asserted that genre is halfway between source and medium. Genre is not necessarily a medium (newspapers, either online or on paper, are a single medium, but each of these forms of dissemination is a different genre), yet nor is it necessarily a source of news (thus, for example, newspapers have social media profiles where they reproduce their news, so in these cases the source would not be the social media - which is a genre- but the medium where the news is posted). However, genre also has points that connect it with the concept of medium (it entails a certain way of editorialising or presenting contents, just as in the media) and with the concept of source (sometimes it is associated with famous brands, such as Facebook and Twitter, when these media provide news from original sources that the user is unfamiliar with or are not strictly news-oriented). Therefore, genre is the format taken by the online news.

In this sense, this research sets out to study how the format or genre of political news on the Internet - format or genre meaning the environment in which this news is embedded and the form it adopts - can affect the perception of credibility, while stressing the distinction between formats common to the traditional media and formats common to the social media because of their central role in propagating news today. We thus posit the following hypotheses: 
Hypothesis 3.1. The credibility assigned to news in the online environment depends on the format in which it is presented (digital newspaper, digital television, Facebook, and WhatsApp).

Hypothesis 3.2. Individuals tend to consider news presented in the online environment in formats common to the traditional media (digital newspaper and digital television) as more credible than news in the online environment presented in formats common to the social media (Facebook and WhatsApp).

\section{Materials and Methods}

To empirically test these hypotheses, a national online survey was designed which is representative of the entire adult population of Spain, with an experimental part inspired by the methodological designs of studies on credibility such as those by Hovland and Weiss (1951-1952), Miller and Kurpius (2010) and Weitz-Shapiro and Winters (2016). Thus, a $4 \times$ 4 experimental design was used which shows four news formats in the online environment (digital newspaper, digital television, Facebook, and WhatsApp) with four generic news items on topics of political interest (immigration, feminism, the far right, and the Lesbian Gay Bisexual Transgender and Queer LGBTQ community). Four experimental groups were created, each of which was exposed to all four news items presented in different formats, such that the same news content is evaluated in a different format by each of the experimental groups.

\subsection{Sample}

The sample was designed by the market study company YouGov Spain based on their online panel. The sample is comprised of 1669 adults representative of the Spanish population as a whole, weighed by sex, age, and region of residence (Nielsen areas) $(n=1669)$. This sample was subdivided into four experimental subgroups of the same size $(n=411, n=435, n=414, n=409)$, which are also representative, who responded to an online survey administered by YouGov Spain between 12 and 17 February 2019. For a confidence level of $95 \%$ and $p=q=0.5$, the overall sample error is $\pm 2.4 \%$.

The sample is comprised of $49 \%$ men $(n=810)$ and $51 \%$ women $(n=859)$. In terms of the age distribution, $8 \%$ are 18 to $24(n=137), 14 \%$ are 25 to $34(n=236), 20 \%$ are 35 to $44(n=332), 19 \%$ are 45 to $54(n=319)$ and $39 \%$ are 55 or older $(n=644)$. Finally, with regard to their region of residence (Nielsen areas), $21 \%$ live in the northeast $(n=349), 15 \%$ on the east coast $(n=242), 24 \%$ in the south $(n=405), 22 \%$ in the centre $(n=363), 10 \%$ in the northwest $(n=158)$ and $9 \%$ in the north $(n=153)$.

\subsection{Experimental News Materials}

In order to ensure that the content of the news evaluated did not affect the perception of credibility, four sets of our news items with exactly the same content were created, but they were presented in the four formats studied. Thus, a news item in the digital newspaper, the television news, the Facebook post, and the WhatsApp message contains exactly the same information, whether written or oral. Obviously, the voiceover in the televised news item is accompanied by images which illustrate the story, but we strove to ensure that they were generic images that could not identify any particular place or person. At the same time, the news item in the digital newspaper, the Facebook post, and the WhatsApp message format are accompanied by a photograph, which is a screenshot of the TV news item.

Television and newspaper were chosen as the traditional media formats because they are the ones used the most by the Spanish population to get the news ${ }^{4}$ while Facebook and WhatsApp were chosen as the social media because they are the are most widely used in Spain to read, see, find, share, or comment on the news ${ }^{5}$.

All four news items used in the experiment correspond to real phenomena reported in televised format by news agencies. The selection criteria are based on two factors: (a) They are relevant, real phenomena yet distanced from the most immediate milieus 
of the respondents to avoid direct knowledge of the story, and (b) Relevant news items were chosen in four topics of political interest which appear recurrently in the media (immigration, feminism, the far right, and the (LGBTQ) community). The selection of these four controversial topics may certainly have an impact on the assessment of credibility by respondents, even though all of them were given a neutral journalistic tone. In this sense, external factors such as a cognitive dissonance (Festinger 1962) between the news item under assessment and the respondents' political beliefs or attitudes towards the topic seem relevant issues to take into consideration. However, this impact is expected to be equally distributed among each one of the experimental groups, which were all representative of the Spanish population. Therefore, despite this probably having an impact in the overall assessment of credibility, it should not affect the differences encountered in the credibility assigned to each one of the formats, which is the main interest of this paper.

To create the televised news items, the original video news stories were edited and processed in order to eliminate any elements that would enable the source to be identified, and they were attributed to a non-existent TV station with an invented logo. To create the written news items, the voiceover of the video news items was turned into writing, and the website of a fictitious digital newspaper was created, as well as a Facebook post and a WhatsApp message also attributed to non-existent media (see samples of the news items created in the Appendix A, Figures A1-A4). In this way, we avoided introducing elements of source credibility or message credibility into the experiment, and we managed to focus the credibility evaluation exclusively on the news items' format or genre.

\subsection{Procedure}

The survey respondents accessed the online survey via a link that they had been sent by YouGov Spain. First, they were warned that they had to have their sound activated in order to answer the questions, and then they were presented with the four different news items in the four aforementioned formats. In each of the four experimental groups, the combinations of topic and format were randomised to neutralise possible sequence biases in the responses (see Table 1).

Table 1. Survey administration procedure for each of the experimental groups.

\begin{tabular}{cccc}
\hline & & Introduction $(n=1669)$ & \\
\hline $\begin{array}{c}\text { Experimental Group 1 } \\
(n=411)\end{array}$ & $\begin{array}{c}\text { Experimental Group 2 } \\
(n=435)\end{array}$ & $\begin{array}{c}\text { Experimental Group 3 } \\
(n=414)\end{array}$ & $\begin{array}{c}\text { Experimental Group 4 } \\
(n=409)\end{array}$ \\
\hline $\begin{array}{c}\text { Immigration-Digital } \\
\text { newspaper }\end{array}$ & $\begin{array}{c}\text { Immigration-Digital } \\
\text { television }\end{array}$ & $\begin{array}{c}\text { Immigration- } \\
\text { Facebook }\end{array}$ & $\begin{array}{c}\text { Immigration- } \\
\text { WhatsApp }\end{array}$ \\
\hline $\begin{array}{c}\text { Feminism-Digital } \\
\text { television }\end{array}$ & Feminism-Facebook & Feminism-WhatsApp & $\begin{array}{c}\text { Feminism-Digital } \\
\text { newspaper }\end{array}$ \\
\hline LGTBQ-Facebook & LGTBQ-WhatsApp & $\begin{array}{c}\text { LGTBQ-Digital } \\
\text { newspaper }\end{array}$ & $\begin{array}{c}\text { LGTBQ-Digital } \\
\text { television }\end{array}$ \\
\hline Far right-WhatsApp & $\begin{array}{c}\text { Far right-Digital } \\
\text { newspaper }\end{array}$ & $\begin{array}{c}\text { Far right-Digital } \\
\text { television }\end{array}$ & Far right-Facebook \\
\hline
\end{tabular}

Questions on interest in the news items on immigration, feminism, LGTBQ and far right $(n=1669)$

LGBTQ = acronym for lesbian, gay, bisexual, transgender and queer.

After viewing each news item but before going on to the next one, the respondents answered two questions related to the credibility they assigned to the news item and the likelihood that they would share it via the social media. At the end of the questionnaire, there were four more questions in which they were asked to evaluate how interested they were in the topics addressed by the news items seen (immigration, feminism, the far right and the LGBTQ community). 


\subsection{Measuring Credibility}

Credibility is clearly a complex, multidimensional concept. Nonetheless, it is also a subjective perception that each person constructs based on criteria which may diverge. In view of this complexity and the need to limit the number of questions asked to such a large number of people in an online survey, we chose to directly ask the respondents about the credibility they assigned to the news items to which they were exposed, using a Likert scale from 1-5 in which 1 meant minimum credibility and 5 maximum credibility. Therefore, credibility was evaluated according to the survey respondents' own implicit and direct definitions, without conditioning them with any pre-established definition. In this sense, we should add that the items comprising the majority of credibility indexes designed by other authors (such as impartiality, truthfulness, or objectivity), as mentioned above, are often as abstract and generic as the very concept of credibility itself. In fact, Meyer (1988) warned that designing the questions to evaluate credibility using other terms could strongly condition the respondents' answers. Therefore, it was deemed preferable to directly question the respondents on their perception of credibility.

In order to examine the relationship between the credibility assigned to the news item in the online environment and the likelihood of sharing it via the social media, a second question was designed which asked the respondents to what extent they would be likely to share the news item they had seen in the social media, with a Likert scale of 1-5 in which 1 meant "I would never do it" and 5 meant "I would do it for sure".

Finally, the association between interest in the topic and the credibility assigned to the news item was evaluated with four questions at the end of the questionnaire which asked the respondents to what extent they were interested in these four topics, with a Likert scale of 1-5 in which 1 meant "no interest" and 5 meant "very interested".

\section{Results}

\subsection{Credibility of Online News According to Format and Topic}

Hypothesis 3.2 stated that individuals assign higher credibility to online news presented in traditional media formats (digital newspapers and digital television) than in social media formats (Facebook and WhatsApp). The hypothesis is valid, since in all four experimental groups the news items assigned the highest credibility are those presented in digital television format, regardless of the topic addressed in this format. Secondly, the news in the digital newspaper format was assigned the highest credibility in three of the four groups (only in the group in which the news on the far right was presented in digital newspaper format was the credibility assigned lower than the news item on feminism, which was presented in Facebook format). The news items in Facebook and WhatsApp format were assigned lower levels of credibility (Table 2).

Table 2. Mean credibility assigned to the online news by format.

\begin{tabular}{|c|c|c|c|c|c|c|c|c|}
\hline \multirow{2}{*}{$\begin{array}{l}\text { Experimental } \\
\text { Group Number }\end{array}$} & \multicolumn{2}{|c|}{ Digital Television } & \multicolumn{2}{|c|}{ Digital Newspaper } & \multicolumn{2}{|c|}{ Facebook } & \multicolumn{2}{|c|}{ WhatsApp } \\
\hline & Mean & $\begin{array}{l}\text { Standard } \\
\text { Deviation }\end{array}$ & Mean & $\begin{array}{l}\text { Standard } \\
\text { Deviation }\end{array}$ & Mean & $\begin{array}{l}\text { Standard } \\
\text { Deviation }\end{array}$ & Mean & $\begin{array}{l}\text { Standard } \\
\text { Deviation }\end{array}$ \\
\hline $\begin{array}{c}\text { Experimental } \\
\text { Group } 1(n=411)\end{array}$ & $\begin{array}{c}4.20 \\
\text { (Feminism) }\end{array}$ & 0.92 & $\begin{array}{c}3.74 \\
\text { (Immigration) }\end{array}$ & 1.06 & $\begin{array}{c}3.22 \\
\text { (LGBTQ) }\end{array}$ & 1.21 & $\begin{array}{c}2.89 \\
\text { (Far right) }\end{array}$ & 1.19 \\
\hline $\begin{array}{c}\text { Experimental } \\
\text { Group } 2(n=435)\end{array}$ & $\begin{array}{c}4.14 \\
\text { (Immigration) }\end{array}$ & 0.97 & $\begin{array}{c}3.17 \\
\text { (Far right) }\end{array}$ & 1.11 & $\begin{array}{c}3.48 \\
\text { (Feminism) }\end{array}$ & 1.09 & $\begin{array}{c}3.09 \\
\text { (LGBTQ) }\end{array}$ & 1.20 \\
\hline $\begin{array}{c}\text { Experimental } \\
\text { Group } 3(n=414)\end{array}$ & $\begin{array}{c}3.99 \\
\text { (LGBTQ) }\end{array}$ & 0.98 & $\begin{array}{c}3.81 \\
\text { (Feminism) }\end{array}$ & 0.98 & $\begin{array}{c}2.88 \\
\text { (Far right) }\end{array}$ & 1.09 & $\begin{array}{c}3.12 \\
\text { (Immigration) }\end{array}$ & 1.31 \\
\hline $\begin{array}{c}\text { Experimental } \\
\text { Group } 4(n=409)\end{array}$ & $\begin{array}{c}3.78 \\
\text { (Far right) }\end{array}$ & 0.97 & $\begin{array}{c}3.47 \\
(\mathrm{LGBTQ})\end{array}$ & 1.18 & $\begin{array}{c}3.34 \\
\text { (Immigration) }\end{array}$ & 1.28 & $\begin{array}{c}3.31 \\
\text { (Feminism) }\end{array}$ & 1.13 \\
\hline
\end{tabular}

Note: credibility measured on a scale of $1-5$, with 1 meaning least credibility and 5 meaning most credibility. (Source: Developed by the authors). 
The average overall credibility assigned to each of the formats (adding together the responses of the 1669 individuals surveyed in relation to the news items on different topics measured on a Likert scale of 1-5) was 4.03 for digital television (SD: 0.97), 3.54 for digital newspapers (SD: 1.11), 3.22 for Facebook (SD: 1.19) and 3.08 for WhatsApp (SD: 1.22). In this sense, despite the difference in formats, it is important to note that in all cases the average credibility assigned materialised in scores which are on the middle or high end of the scale. Therefore, no format is assigned low or very low credibility.

In order to validate that the format of online news indeed affects the credibility assigned (Hypothesis 3.1), an Analysis of Variance (ANOVA) test was conducted with format and topic of the news (feminism, immigration, far right, and LGTBQ) as factors and with age, gender, and interest in the topic as covariables. The results show the format has a significant effect on the levels of credibility assigned (F: 241,332). Moreover, we observed that the topic of the news item also affects credibility, although it does so to a lesser extent (F: 67,569) (Table 3).

Table 3. ANOVA test. Credibility as dependent variable.

\begin{tabular}{cccccc}
\hline \multicolumn{5}{c}{ ANOVA TEST 1 } \\
\hline Dependent Variable: Credibility & & \\
\hline Source & $\begin{array}{c}\text { Type III Sum of } \\
\text { Squares }\end{array}$ & df & $\begin{array}{c}\text { Mean } \\
\text { Square }\end{array}$ & F & Sig. \\
\hline $\begin{array}{c}\text { Corrected } \\
\text { Model }\end{array}$ & 1337.166 a & 18 & 74.287 & 61.725 & 0 \\
\hline Intersect & 1196.02 & 1 & 1196.02 & 993.767 & 0 \\
\hline Age & 102.311 & 1 & 102.311 & 85.01 & 0 \\
\hline Gender & 2.359 & 1 & 2.359 & 1.96 & 0.162 \\
\hline Interest & 93.386 & 1 & 93.386 & 77.594 & 0 \\
\hline News Format & 871.345 & 3 & 290.448 & 241.332 & 0 \\
\hline News Topic & 243.962 & 3 & 81.321 & 67.569 & 0 \\
\hline $\begin{array}{c}\text { News Format } \\
\text { News Topic }\end{array}$ & 16.525 & 9 & 1.836 & 1.526 & 0.133 \\
\hline Error & 8011.841 & 6657 & 1.204 & \\
\hline Total & 89521 & 6676 & & \\
\hline Corrected \\
Total
\end{tabular}

Furthermore, there are significant correlations between the credibility assigned to each of the formats, regardless of the topic of the news item; that is, the respondents who tended to assign higher credibility scores to a given format also assigned higher scores to the other formats. However, these correlations are stronger between the two types of formats: digital television and digital newspapers on the one hand, and Facebook and WhatsApp on the other (Table 4). 
Table 4. Correlation coefficients of credibility in each format.

\begin{tabular}{|c|c|c|c|c|}
\hline Format & $\begin{array}{l}\text { Credibility-Digital } \\
\text { Television }(n=1669)\end{array}$ & $\begin{array}{l}\text { Credibility-Digital } \\
\text { Newspaper }(n=1669)\end{array}$ & $\begin{array}{c}\text { Credibility- } \\
\text { Facebook } \\
(n=1669)\end{array}$ & $\begin{array}{c}\text { Credibility- } \\
\text { WhatsApp } \\
(n=1669)\end{array}$ \\
\hline $\begin{array}{c}\text { Credibility_-Digital Television } \\
\qquad(n=1669)\end{array}$ & 1 & $0.331^{* * *}$ & $0.285^{* * *}$ & $0.239 * * *$ \\
\hline $\begin{array}{l}\text { Credibility-Digital } \\
\text { newspaper }(n=1669)\end{array}$ & & 1 & $0.207^{* * *}$ & $0.310^{* * *}$ \\
\hline $\begin{array}{l}\text { Credibility_Facebook } \\
\qquad(n=1669)\end{array}$ & & & 1 & $0.348^{* * *}$ \\
\hline $\begin{array}{c}\text { Credibility-WhatsApp } \\
\qquad(n=1669)\end{array}$ & & & & 1 \\
\hline
\end{tabular}

Note: Pearson correlation analysis was performed. The correlation analyses are based on a two-tailed test. ${ }^{* * *} p<0.001$. (Source: Developed by the authors).

Hypothesis 1.2 focused on how the interest in certain topics may be associated with the credibility assigned to the news items referring to these topics. Below (Table 5) we show the average scores on the interest that the respondents expressed in each of the topics that were part of the survey:

Table 5. Interest in the different news topics.

\begin{tabular}{ccc}
\hline Topic & M & SD \\
\hline Feminism $(n=1669)$ & 3.61 & 1.23 \\
\hline Immigration $(n=1669)$ & 3.44 & 1.19 \\
\hline LGBTQ $(n=1669)$ & 3.45 & 1.31 \\
\hline Far Right $(n=1669)$ & 3.70 & 1.35
\end{tabular}

Note: Interest measured on a scale of 1-5, with 1 meaning least interest and 5 meaning most interest. (Source: Developed by the authors).

The previous ANOVA test showed how the variables "interest in the topic" and "age" (Hypothesis 2) also had a significant impact on the credibility assigned. In this sense, a multiple linear regression was carried out with the dependent variable "News credibility" and the rest of the variables as predictors (except for variable "Gender", due to its nonsignificant result in the previous ANOVA test) (Table 6). With this model, we can confirm the strong association between credibility and news format (F: -0.0225$)$. However, there are also moderate associations with "age" (F: 0.072) and "news topic" (F: -0.071). Finally, the variable "interest in the topic" (F: 0.032 ) has the lowest association with credibility. It should also be noted that R squared is fairly high (0.363).

Thus, looking at the hypotheses previously posed, we observe that a greater interest in a specific topic is associated with assigning higher credibility scores to the news referred to it. Moreover, young people are generally those who assign lower credibility scores to the news, in comparison with older people, while the hypothesis predicted the opposite. 
Table 6. Multiple Linear Regression. Credibility as dependent variable.

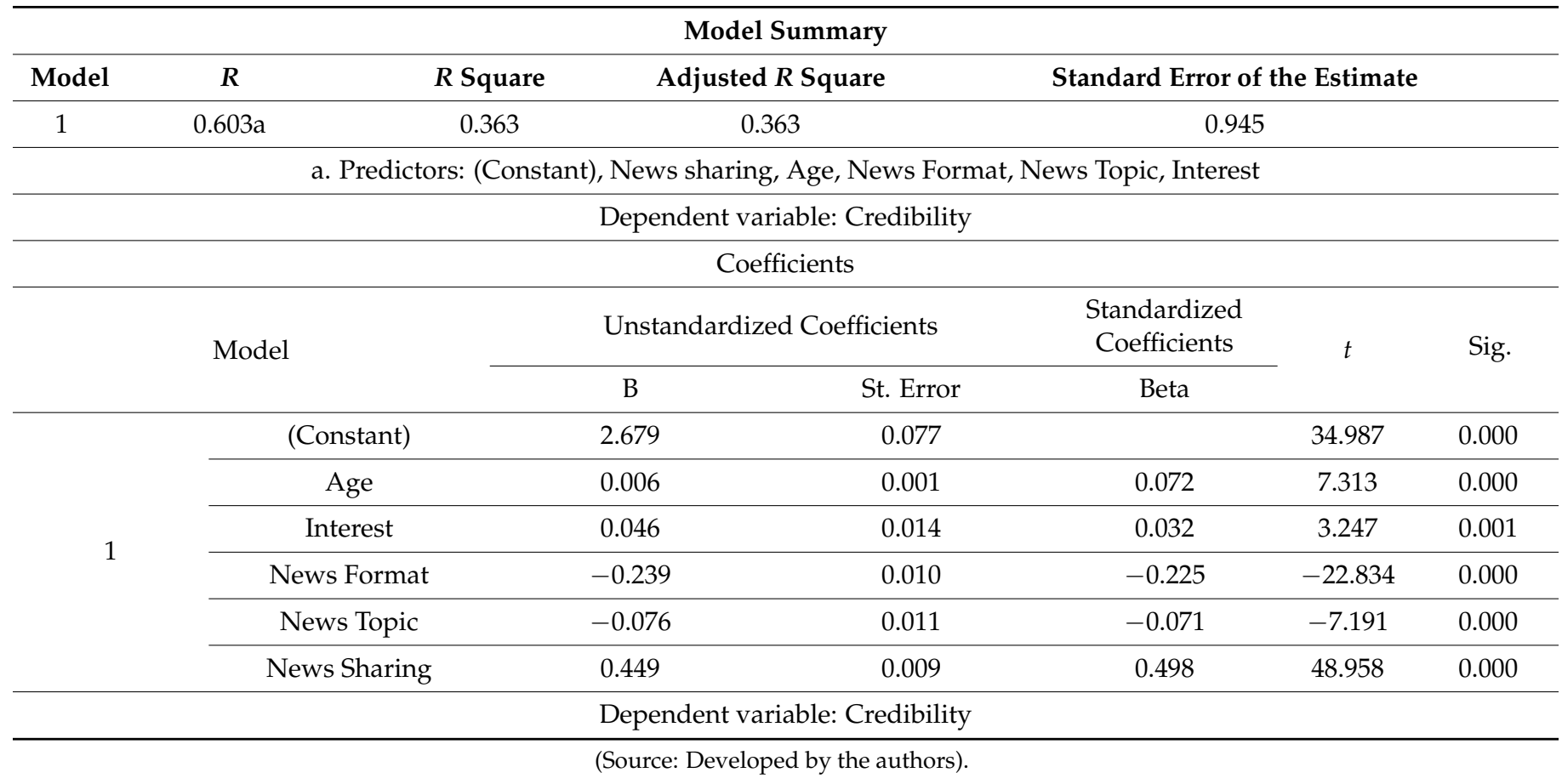

\subsection{Credibility and Sharing News Items in the Social Media}

Hypothesis 1.1 sought to evaluate to what extent the credibility assigned to a news item was related to the desire to share it via social media; if this association were to be validated, the action of sharing could be pinpointed as a behaviour indicative of the credibility assigned. Table 7 shows the respondents' average responses to the question of the likelihood that they think they would share the different news items they were presented via social media, according to the format in which they saw the news. As it can be seen, likelihood of sharing is higher in those news formats with higher credibility scores, and vice versa.

On the other hand, the ANOVA test conducted in relation to the willingness to share according to the format show that format matters, just as with assigned credibility (Table 8). Thus, a greater likelihood of sharing generally occurs with formats which are considered more credible, regardless of the topic of the news item, which reinforces Hypothesis 1.1. In this sense, the likelihood of sharing in any of the formats (adding together the responses of the 1669 respondents in relation to news items on different topics, measured on a 1-5 Likert scale) was 2.87 for digital television (SD: 1.36), 2.54 for digital newspapers (SD: 1.28), 2.39 for Facebook (SD: 1.28) and 2.37 for WhatsApp (SD: 1.27). Therefore, this reproduces the format order found in the case of credibility, although the differences in scores between the formats in relation to the likelihood of sharing on the social media are lower, and the overall averages are also lower. 
Table 7. Likelihood to share the news items via the social media, by format.

\begin{tabular}{|c|c|c|c|c|c|c|c|c|}
\hline \multirow[t]{2}{*}{$\begin{array}{c}\text { Experimental } \\
\text { Group Number }\end{array}$} & \multicolumn{2}{|c|}{ Digital Television } & \multicolumn{2}{|c|}{ Digital Newspaper } & \multicolumn{2}{|c|}{ Facebook } & \multicolumn{2}{|c|}{ WhatsApp } \\
\hline & $\mathbf{M}$ & SD & $\mathbf{M}$ & SD & $\mathbf{M}$ & SD & $\mathbf{M}$ & SD \\
\hline $\begin{array}{c}\text { Experimental } \\
\text { Group } 1(n=411)\end{array}$ & $\begin{array}{c}3.32 \\
\text { (Feminism) }\end{array}$ & 1.39 & $\begin{array}{c}2.68 \\
\text { (Immigration) }\end{array}$ & 1.33 & $\begin{array}{c}2.46 \\
\text { (LGTBQ) }\end{array}$ & 1.30 & $\begin{array}{c}2.18 \\
\text { (Far right) }\end{array}$ & 1.18 \\
\hline $\begin{array}{c}\text { Experimental } \\
\text { Group } 2(n=435)\end{array}$ & $\begin{array}{c}2.82 \\
\text { (Immigration) }\end{array}$ & 1.32 & $\begin{array}{c}2.18 \\
\text { (Far right) }\end{array}$ & 1.14 & $\begin{array}{c}2.79 \\
\text { (Feminism) }\end{array}$ & 1.31 & 2.42 (LGTBQ) & 1.27 \\
\hline $\begin{array}{c}\text { Experimental } \\
\text { Group } 3(n=414)\end{array}$ & $\begin{array}{c}2.88 \\
\text { (LGTBQ) }\end{array}$ & 1.30 & $\begin{array}{c}2.89 \\
\text { (Feminism) }\end{array}$ & 1.31 & $\begin{array}{c}1.94 \\
\text { (Far right) }\end{array}$ & 1.10 & $\begin{array}{c}2.30 \\
\text { (Immigration) }\end{array}$ & 1.27 \\
\hline $\begin{array}{c}\text { Experimental } \\
\text { Group } 4(n=409)\end{array}$ & $\begin{array}{c}2.50 \\
\text { (Far right) }\end{array}$ & 1.30 & 2.46 (LGTBQ) & 1.26 & $\begin{array}{c}2.38 \\
\text { (Immigration) }\end{array}$ & 1.28 & $\begin{array}{c}2.63 \\
\text { (Feminism) }\end{array}$ & 1.32 \\
\hline
\end{tabular}

Note: Likelihood to share measured on a scale of 1-5, with 1 meaning least likely and 5 meaning most likely. (Source: Developed by the authors).

Table 8. ANOVA test. Likelihood of sharing as dependent variable.

\section{ANOVA TEST 2}

Dependent Variable: Sharing the News

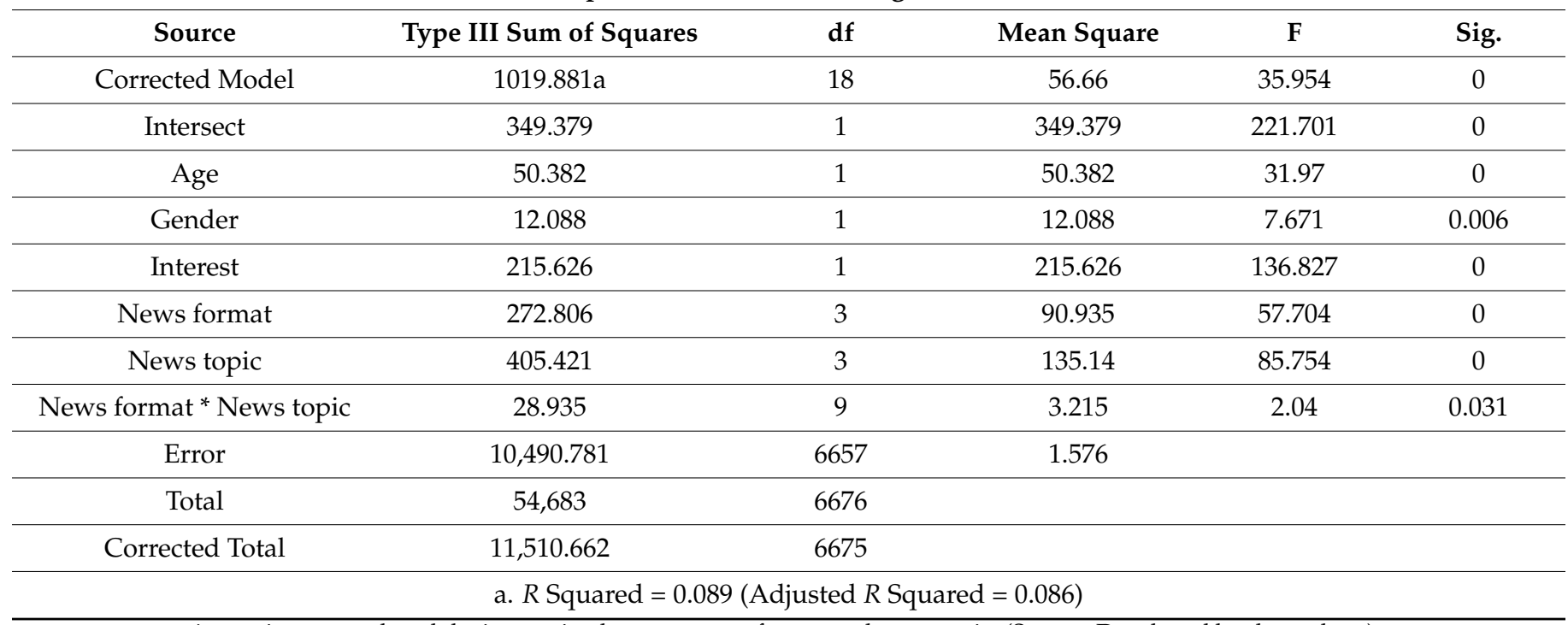

${ }^{*}$ meaning we analyzed the interaction between news format and news topic. (Source: Developed by the authors).

Moreover, the multiple linear regression (Table 9) confirms the strong positive relationship between credibility assigned to the news and likelihood of sharing it, with an F coefficient of 0.53 . A significant association between interest in the topic and likelihood of sharing the news is also remarkable (F: 0.089), just as it occurred when credibility was assessed. Furthermore, it is interesting to note that the multiple regression offers a value of 0.321 for $R$, a much more explanatory result than the one from the ANOVA test. On the contrary, age does not seem to be a factor associated with likelihood of sharing the news, despite being significant when assessing credibility. 
Table 9. Multiple Linear Regression. Likelihood of sharing as dependent variable.

\begin{tabular}{ccccc}
\hline Model & $\boldsymbol{R}$ & $\boldsymbol{R}$ Square & Adjusted $\boldsymbol{R}$ Square & $\begin{array}{c}\text { Standard Error of } \\
\text { the Estimate }\end{array}$ \\
\hline 1 & $0.567 \mathrm{a}$ & 0.322 & 0.321 & 1.082 \\
\hline
\end{tabular}

a. Predictors: (Constant), Credibility, gender, age, News topic, interest, News format

b. Dependent variable: News sharing

\begin{tabular}{|c|c|c|c|c|c|c|}
\hline \multicolumn{7}{|c|}{ Model } \\
\hline Model & $\begin{array}{l}\text { Unstandardized } \\
\text { Coefficients }\end{array}$ & $\begin{array}{l}\text { Standardized } \\
\text { Coefficients }\end{array}$ & $t$ & Sig. & $t$ & Sig. \\
\hline & & B & St. Error & Beta & & \\
\hline \multirow[t]{7}{*}{1} & (Constant) & 0.095 & 0.099 & & 0.957 & 0.339 \\
\hline & Age & 0.001 & 0.001 & 0.01 & 1.023 & 0.306 \\
\hline & Gender & 0.064 & 0.027 & 0.024 & 2.342 & 0.019 \\
\hline & Interest & 0.139 & 0.016 & 0.089 & 8.513 & 0 \\
\hline & News topic & -0.108 & 0.012 & -0.092 & -9.015 & 0 \\
\hline & News format & 0.018 & 0.012 & 0.016 & 1.479 & 0.139 \\
\hline & Credibility & 0.589 & 0.012 & 0.53 & 48.928 & 0 \\
\hline & & a. Depe & le: News & & & \\
\hline
\end{tabular}

\section{Discussion and Limitations}

As Martin and Hassan (2020) pointed out, news credibility perceptions predict online fake news exposure, at least in certain countries. The study of news credibility is thus particularly relevant in the current context of concern about the spread of disinformation. With this research, we sought to study how three different factors (the format of the news in an online environment, respondents' interest in certain topics which repeatedly appear in the media, and age) may influence people's perceptions of the credibility of online news in Spain, and we also sought to analyse the relationship between the credibility of the news items in the online environment and the likelihood of sharing them via the social media.

Relatively few years ago, the Internet was considered yet another medium in studies on media credibility, but today it is clear that this makes little sense. Thus, in this study we analysed how the format of the online news (a concept similar to genre coined by Flanagin and Metzger 2007) may be related to credibility. The design and administration of an experimental survey to a representative sample of the adult Spanish population as a whole enabled us to conclude that format does indeed affect perceptions of credibility, regardless of the topic addressed by the news items. The results show that news items presented in formats native to the traditional media (digital television and digital newspapers) are viewed as more credible than those presented in formats native to the social media (Facebook and WhatsApp), as also found in Johnson and Kaye (2014), revealing a more cautious attitude towards news that circulates in the social media. However, the high degree of credibility assigned to news items in the digital television format compared to the digital newspaper format is to some extent surprising, given that outside the online environment, newspapers seem to have the highest levels of credibility (Flanagin and Metzger 2000; Kiousis 2001). We should also note that, generally speaking, the levels of credibility assigned to the news in the online environment are moderately high in all the formats studied, meaning that we found an important level of trust in the online media as well, just as Roses and Gómez-Calderón (2015) did. Considering that Facebook and WhatsApp are highly associated with disinformation and fake news, this is a surprising finding that poses a debate on whether citizens are aware enough of the potential drawbacks and perils of social media as a source of news. Further research seems necessary to better explore these issues. 
Finally, we question whether the results of this study would have been significantly different if we had measured credibility not as a simple variable to which the participants respond but as a composite index of different variables, as done in the majority of studies in the field. Regardless, we believe that it makes sense to study individual perceptions, such as the perception of credibility, by directly asking the survey population to take a position on this factor, without resorting to terms which indirectly refer to it. We also wonder whether a different instrument for assessing credibility (for example, a 1-7 Likert scale instead of a 1-5 Likert scale) would have produced significantly different results on the credibility assigned to the formats under scrutiny. It seems plausible to think that a larger scale would have produced bigger differences in credibility among formats, which in turn would have allowed a better understanding and explanation of these differences in relation to variables such as age or interest in the topic. However, this is something to be assessed in future studies. Obviously, the other major doubt remaining is whether in other countries the results of this experimental survey would be similar to the ones we described here.

\section{Conclusions}

The differences in credibility between media in the offline environment, or old media, are not reproduced when comparing online news formats. In any case, it seems clear that the higher credibility assigned to news in the digital television format may indicate that news in this format more easily lends itself to spreading disinformation. As Kiousis (2001) pointed out, the existence of images may provide televised news with the appearance of greater credibility.

Furthermore, we found that there are significant correlations between the levels of credibility assigned to the news items in different formats, which indicates that the people who assign high credibility to one format also tend to evaluate the other formats as highly credible. The associations are stronger between digital television and digital newspapers and between Facebook and WhatsApp, which might indicate that each type of format (traditional media or social media) generates more similar perceptions of credibility.

Compared to format, age and interest in the topic are factors that are less explanatory of credibility. With regard to age, we found a slight positive correlation between age and credibility, which is more pronounced in the news items presented in social media formats. Young people seem to be more critical with online news items, especially when they appear in social media formats, whereas older people show a stronger tendency to assign credibility to this type of news. These results corroborate those found by Choi and Kim (2017) and contradict the hypothesis posited in this research, which assumed a less critical attitude among young people. They also point to a possible future avenue of research in this direction to learn more about this phenomenon, by introducing new variables in the relationship between age and credibility that may help understand the divergent conclusions posed by different studies on this issue. In any case, it can be assumed that younger people's greater expertise or mastery of the new language and new platforms contributes to their being more watchful and cautious when assigning credibility to the news items that reach them via WhatsApp and Facebook.

On the other hand, interest in the topic of the news items presented in the experiment (feminism, immigration, far right, and LGTBQ) is also correlated with credibility, albeit not strongly, such that the more interest the individuals show in a topic the more credibility they tend to assign to the news item which mentions it, regardless of the format in which it is presented. This result is particularly interesting and leads us to question to what extent personal interests, beliefs, and attitudes can lead to a suspension of individuals' critical judgement due to cognitive dissonance processes. Further study is needed to explore these factors in more depth. It should be noted that among all the news topics presented to the respondents, the "far right" topic led to results that differ somehow from the others. It is the news item in which the respondents expressed the keenest interest, and also the one in which this interest is the least correlated with the credibility assigned, as well as 
being the only topic in which there is no correlation between age and credibility. All of this could be related to the fact that news items on this topic have always been assessed as less credible in all formats, although it also enables us to posit hypotheses such as the fact that it is a socially delicate topic which "distorts" the results compared to the results of the news items on the other topics, which are perhaps not quite as "thorny".In terms of sharing news via the social media, this is a factor that is clearly associated with credibility. We believe it may be useful to include this factor in studies on the credibility of news in the online environment to help predict whether credibility will be assigned, especially in relation to news that is spread via WhatsApp, a social app particularly suitable for sharing information among close contacts. However, it is interesting to note that sharing news items is not clearly associated with age, as in the case of credibility. In this sense, one hypothesis could be that older people (who tend to assign more credibility to news and therefore, in theory, should tend to share it more) are not as familiar with social media and consequently less likely to share news by this means.

Author Contributions: Conceptualization, R.B. and C.P.-S.; methodology, R.B.; formal analysis, R.B.; investigation, R.B. and C.P.-S.; resources, R.B. and C.P.-S.; data curation, R.B. and C.P.-S.; writingoriginal draft preparation, R.B. and C.P.-S.; writing - review and editing, R.B. and C.P.-S.; supervision, R.B. and C.P.-S.; project administration, C.P.-S.; funding acquisition, C.P.-S. All authors have read and agreed to the published version of the manuscript.

Funding: This research was funded by the Ideograma-UPF Chair of Political Communication and Democracy (https: / / www.upf.edu/web / catedra-ideograma (accessed on 7 May 2021)).

Institutional Review Board Statement: Not applicable.

Informed Consent Statement: Not applicable.

Data Availability Statement: The data presented in this study are available on request from the corresponding author. The data are not publicly available due to the fact that they were collected by the private market research company YouGov Spain within its panel.

Conflicts of Interest: The authors declare no conflict of interest. The funders had no role in the design of the study; in the collection, analyses, or interpretation of data; in the writing of the manuscript, or in the decision to publish the results.

\section{Appendix A}

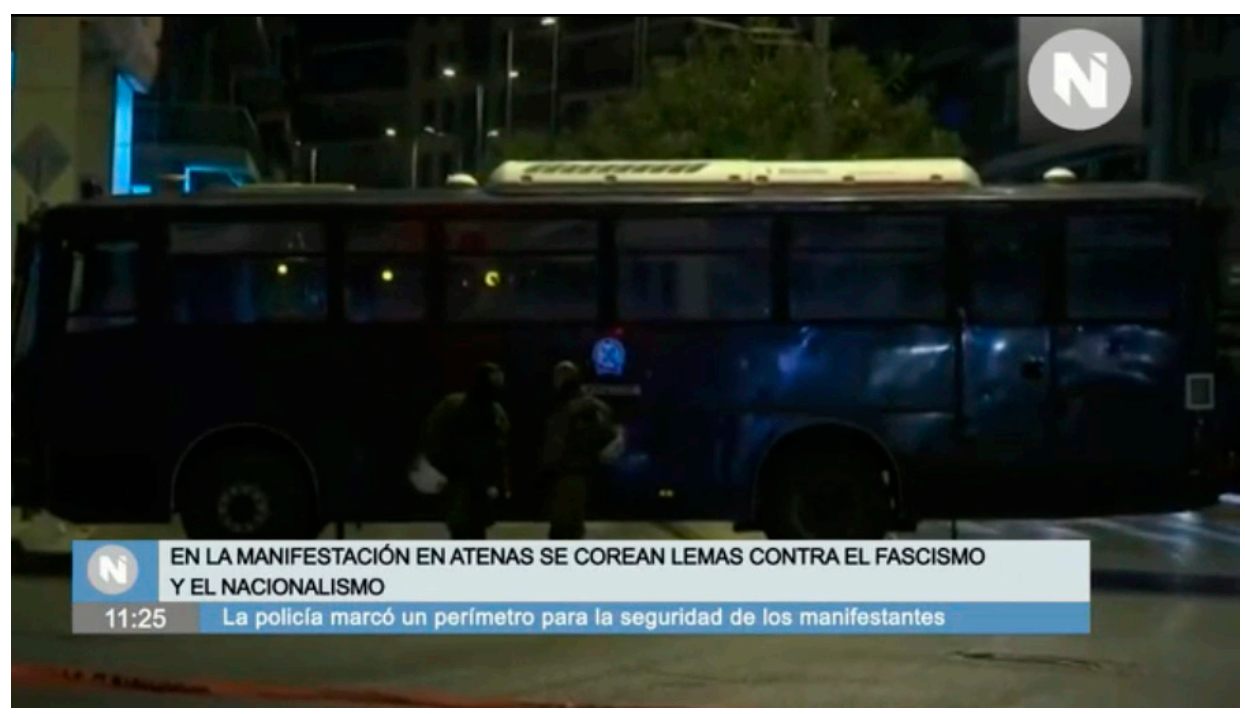

Figure A1. Sample of the news item on the far right in digital television format. 
Es noticia | Japón y la UE llcgan a un acucrdo coconómico histórion. Es mucho más quo un simple pacto do cooperación

Siguenosen $\boldsymbol{f} \boldsymbol{y}(0) \quad$ Inicio sesión | Registro $\boldsymbol{\theta}$ >

INDEPENDIENTE

Internacional Economiav Sociedad Familiav Opinión* Deportes* Gentev Cultura * Clencia Historia Viajar* Play* Mäs $\equiv$

La extrema derecha griega toma las calles de

Atenas coreando lemas contra Turquía

- Un cordón policial de autobuses ha bloqueado el acceso al parlamento griego

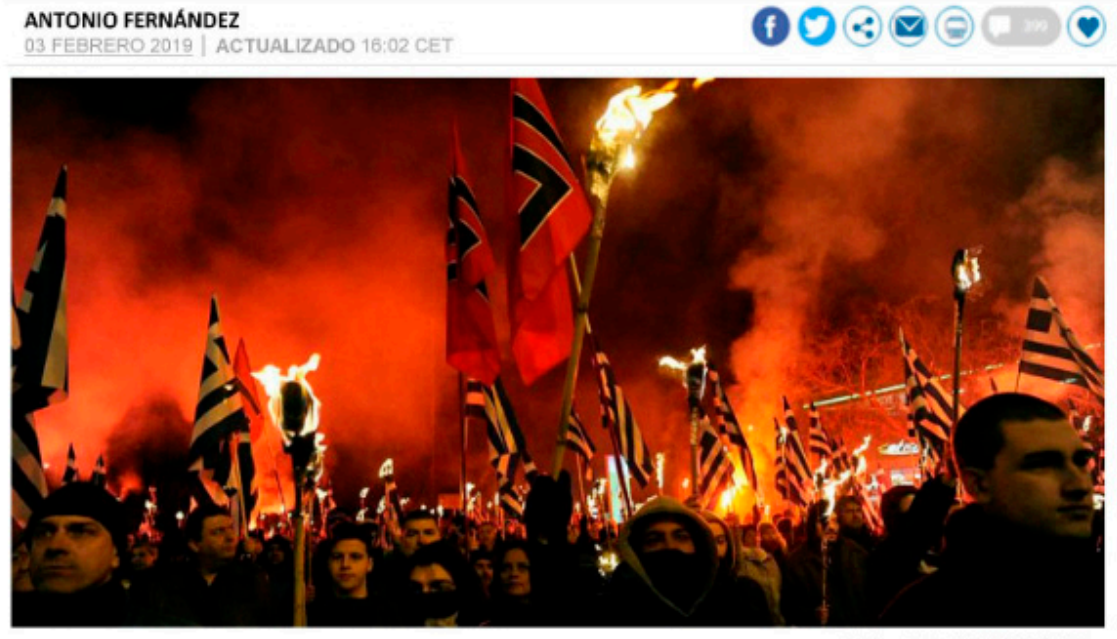

Q Copyright: INDEPENDIENTE

El Partido Amanecer Dorado ha organizado la marcha anual, a la que asistieron unos 2.000 simpatizantes de la formación ultraderechista. Se congregaron en las cercanias del parlamento para conmemorar la crisis de Imia-Kardak de 1996, en la que Grecia y Turquia estuvieron a punto de entrar en guerra por la disputa sobre un islote deshabitado y en la que fallecieron tres pilotos griegos.

Más de 20 años después de este episodio, la extrema derecha griega acusa a Turquia de no frenar la llegada de refugiados e inmigrantes a las costas europeas.

El abogado de Amanecer Dorado, llias Panagiotaros, declarado que "su pais es un campo abierto, vienen y se van cuando quieren. Nos gustaria tener una política como la que Donald Trump está llevando a cabo en Estados Unidos".

En el mismo momento y también en Atenas se ha celebrado una contramanifestación en la que se han coreado lemas contra el fascismo y el nacionalismo. La policía ha establecido un perimetro de seguridad para evitar posibles choques entre los participantes de las dos manifestaciones.

Figure A2. Sample of the news item on the far right in digital newspaper format. Translation: A Greek far-right demonstration takes control of the streets of Athens chanting slogans against Turkey. A cordon of police vans has blocked access to the Greek Parliament The far-right party Golden Sunrise organized its annual march which saw an attendance of 2000 supporters. They met near the Greek Parliament to commemorate the 1996 crisis of Imia-Kardak in which Greece and Turkey were close to starting a military conflict over the control of an uninhabited island that ended in the death of 3 Greek pilots. Over twenty years since that incident, the Greek far-right movement has accused Turkey of allowing the arrival of refugees and immigrants to European coasts. Golden Sunrise's lawyer, Ilias Panagiotaros, declares that Greece "has an open-door policy, they come and go whenever they want. We would like to have policies similar to the ones which are being carried out by Donald Trump in the USA". At the same time, a counter-demonstration took place in Athens, the main motto of which was a message against fascism and nationalism. The police established a security perimeter to avoid any kind of clash between the two groups of supporters. 


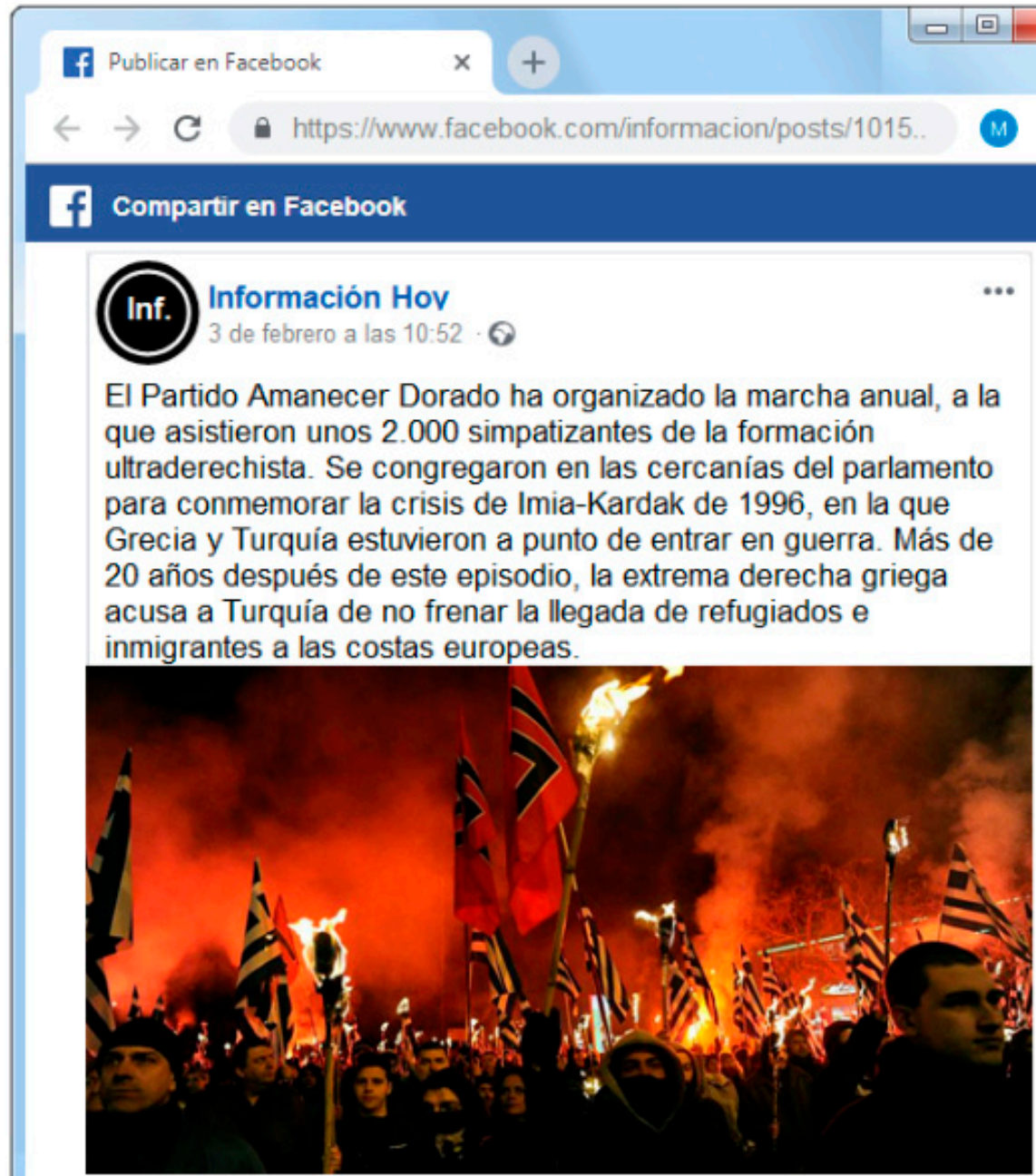

INFORMACION.COM

\section{La extrema derecha griega toma las calles de Atenas coreando lemas contra Turquia}

Un cordón policial de autobuses ha bloqueado el acceso al parlamento griego.

(1) 8352

347 comentarios 82 veces compartido
D. Me gusta
Comentar
$\Leftrightarrow$ Compartir

Más relevantes *

Figure A3. Sample of the news item on the far right in Facebook format. 


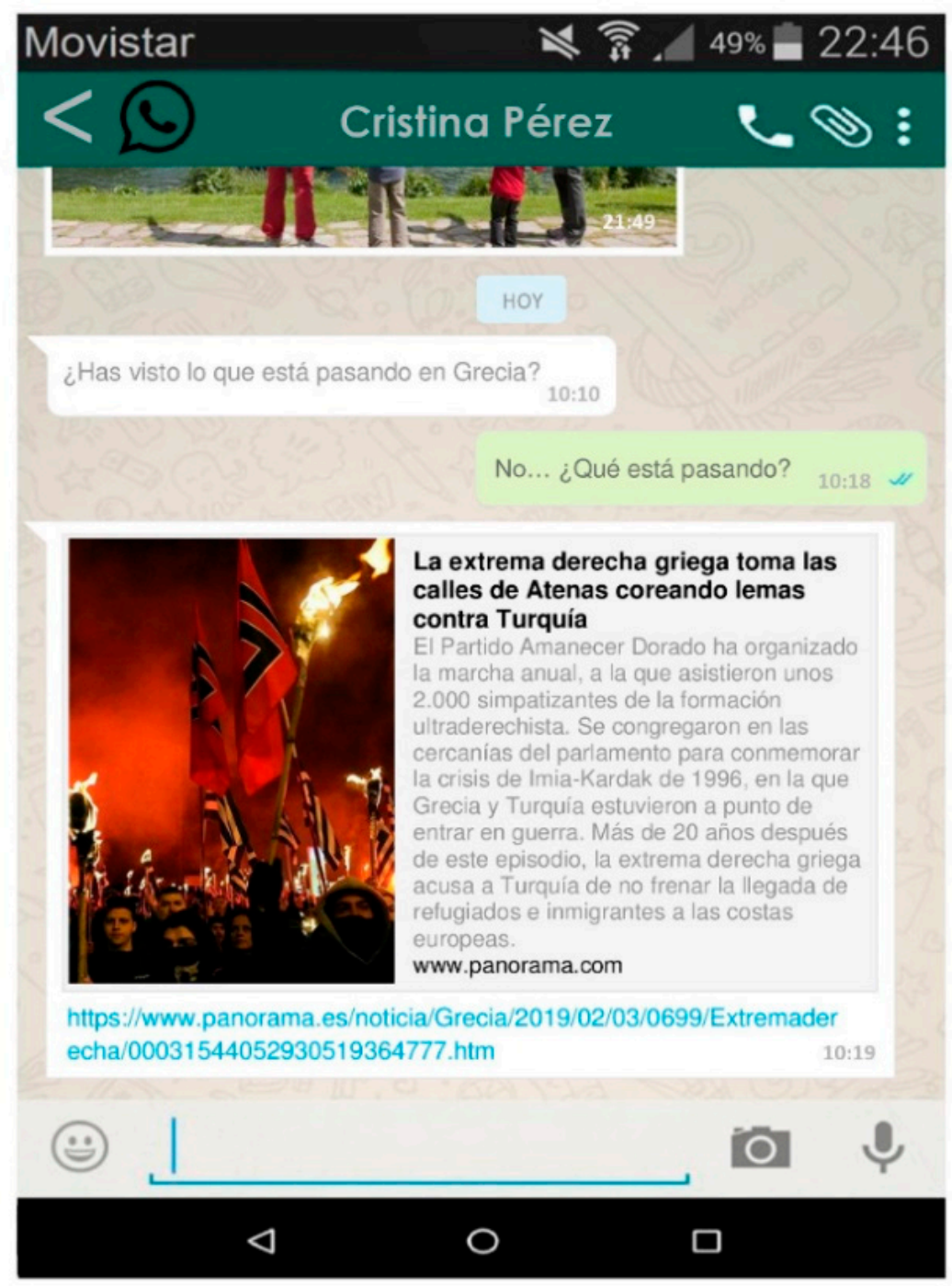

Figure A4. Sample of the news item on the far right in WhatsApp format.

\section{Notes}

1 Fallon, Claire. 2017. Where does the term "fake news" come from? The 1890s, apparently. HuffPost. Retrieved from http: / / www.huffingtonpost.com/entry/where-does-the-termfake-newscome-from_us_58d53c89e4b03692 bea518ad (accessed on 7 May 2021).

2 Figures from Digital News Report 2015. https://reutersinstitute.politics.ox.ac.uk/sites/default/files/research/ files/Reuters\%2520Institute\% 2520Digital\%2520News\%2520Report\%25202015_Full\%2520Report.pdf (accessed on 7 May 2021).

3 Figures from Pew Research Center 2018. https://www.journalism.org/2018/05/14/in-westerneurope-publicattitudes-toward-news-media-more-divided-by-populist-views-than-left-rightideology/ (accessed on 7 May 2021).

4 Figures from the Digital News Report 2019 for Spain: https://www.digitalnewsreport.es/2019/el--45--de--los--usuarios-elige--la--television--como--medio--principal--para--informarse--mientras--el--40--opta--por--las--fuentes--online/ (accessed on 7 May 2021).

5 Once again, see the Digital News Report 2019 for Spain: https:/ /www.digitalnewsreport.es/2019/facebook--whatsapp--y-youtube--lideran--en--redes--pero--instagram--y--facebook--messenger--emergen--para--uso--informativo/ (accessed on 7 May 2021).

\section{References}

Bennett, Lance, and Steven Livingston. 2018. The disinformation order: Disruptive communication and the decline of democratic institutions. European Journal of Communication 33: 122-39. [CrossRef] 
Bernal-Triviño, Ana, and Judith Clares-Gavilán. 2019. Uso del móvil y las redes sciales como canales de verificación de fake news. El caso de Maldita.es. El Profesional de la Información 28: e280312. [CrossRef]

Blach-Ørsten, Mark, and Rasmus Burkal. 2014. Credibility and the media as a political institution. Nordicom Review 35: 67-79. [CrossRef]

Bucy, Erik Page. 2003. Media credibility reconsidered: Synergy effects between on-air and online news. Journalism and Mass Communication Quarterly 80: 247-64. [CrossRef]

Bucy, Erik Page, Paul D'Angelo, and Nichole M. Bauer. 2014. Crisis, credibility, and the press: A priming model of news evaluation. The International Journal of Press/Politics 19: 453-75. [CrossRef]

Choi, Sujin, and Jeongseob Kim. 2017. Online news flow: Temporal/spatial exploitation and credibility. Journalism 18: 1184-205. [CrossRef]

Chung, Chung Joo, Yoonjae Nam, and Michael A. Stefanone. 2012. Exploring online news credibility: The relative influence of traditional and technological factors. Journal of Computer-Mediated Communication 17: 171-86. [CrossRef]

Festinger, Leon. 1962. Cognitive dissonance. Scientific American 207: 93-106. [CrossRef]

Flanagin, Andrew, and Miriam Metzger. 2000. Perceptions of internet information credibility. Journalism and Mass Communication Quarterly 77: 515-40. [CrossRef]

Flanagin, Andrew, and Miriam Metzger. 2007. The role of site features, user attributes, and information verification behaviors on the perceived credibility of web-based information. New Media and Society 9: 319-42. [CrossRef]

Fogg, B. J., Jonathan Marshall, Othman Laraki, Alex Osipovich, Chris Varma, Nicholas Fang, Jyoti Paul, Akshay Rangnekar, John Shon, Preeti Swani, and et al. 2001. What makes web sites credible? A report on a large quantitative study. CHI 3: 61-68. [CrossRef]

Giglietto, Fabio, Laura Iannelli Valeriani, and Augusto Luca Rossi. 2019. 'Fake news' is the invention of a liar: How false information circulates within the hybrid news system. Current Sociology 67: 625-42. [CrossRef]

Go, Eun, Kyung Han You, Eunhwa Jung, and Hongjin Shim. 2016. Why do we use different types of websites and assign them different levels of credibility? Structural relations among users' motives, types of websites, information credibility, and trust in the press. Computers in Human Behavior 54: 231-39. [CrossRef]

Hmielowski, Jay D., Sarah Staggs, Myiah J. Hutchens, and Michael A. Beam. 2020. Talking politics: The relationship between supportive and opposing discussion with partisan media credibility and use. Communication Research. [CrossRef]

Hong, Jungmin. 2021. Translation of attribution and news credibility. Journalism 22: 787-803. [CrossRef]

Hovland, Carl I., and Walter Weiss. 1951-1952. The influence of source credibility on communication effectiveness. The Public Opinion Quarterly 15: 635-50. [CrossRef]

Johnson, Thomas J., and Barbara K. Kaye. 1998. Cruising is believing? Comparing internet and traditional sources on media credibility measures. Journalism and Mass Communication Quarterly 75: 325-40. [CrossRef]

Johnson, Thomas J., and Barbara K. Kaye. 2014. Credibility of social network sites for political information among politically interested internet users. Journal of Computer-Mediated Communication 19: 957-74. [CrossRef]

Kiousis, Spiro. 2001. Public trust or mistrust? Perceptions of media credibility in the information age. Mass Communication and Society 4: 381-403. [CrossRef]

Martin, Justin D., and Fouad Hassan. 2020. News media credibility ratings and perceptions of online fake news exposure in five countries. Journalism Studies 21: 2215-33. [CrossRef]

Meyer, Philip. 1988. Defining and measuring credibility of newspapers: Developing an index. Journalism Quarterly 65: 567-74. [CrossRef]

Miller, Andrea, and David Kurpius. 2010. A citizen-eye view of television news source credibility. American Behavioral Scientist 54: 137-56. [CrossRef]

Pjesivac, Ivanka, Nicholas Geidner, and Jaclyn Cameron. 2018. Social credibility online: The role of online comments in assessing news article credibility. Newspaper Research Journal 39: 18-31. [CrossRef]

Rodríguez-Fernández, María-Magdalena, Valentín-Alejandro Martínez-Fernández, and Óscar Juanatey-Boga. 2020. Credibilidad en la prensa online: Estrategia para la diferenciación y generación de audiencias. Profesional de la Información 29. [CrossRef]

Roses, Sergio, and Bernardo Gómez-Calderón. 2015. Credibilidad de los medios en España: Divergencias de percepción y caracterización de los escépticos. El Profesional de la Información 24: 432-39. [CrossRef]

Sundar, Shyam S. 1999. Exploring receivers' criteria for perception of print and online news. Journalism and Mass Communication Quarterly 76: 373-86. [CrossRef]

Tsfati, Yariv. 2010. Online news exposure and trust in the mainstream media: Exploring possible associations. American Behavioral Scientist 54: 22-42. [CrossRef]

Tuchman, Gaye. 1978. Making News: A Study in The Construction of Reality. New York: Free Press.

Vargo, Chris J., Lei Guo, and Michelle A. Amazeen. 2018. The agenda-setting power of fake news: A big data analysis of the online media landscape from 2014 to 2016. New Media and Society 20: 2028-49. [CrossRef]

Varona-Aramburu, David, Milagrosa Sánchez-Martín, and Roberto Arrocha. 2017. Consumo de información política en dispositivos móviles en España: Caracterización del usuario tipo y su interacción con las noticias. El profesional de la información 26: 641-8. [CrossRef]

Weitz-Shapiro, Rebecca, and Matthew S. Winters. 2016. Can citizens discern? Information credibility, political sophistication, and the punishment of corruption in Brazil. The Journal of Politics 79: 60-74. [CrossRef] 